\title{
A Test of Taxonomic Predictivity: Resistance to Early Blight in Wild Relatives of Cultivated Potato
}

\author{
S. H. Jansky, R. Simon, and D. M. Spooner
}

First and third authors: U.S. Department of Agriculture-Agricultural Research Service, Department of Horticulture, University of Wisconsin, Madison, 53706; and second author: International Potato Center, P.O. Box 1558, La Molina, Lima 12, Peru. Accepted for publication 1 February 2008.

\section{ABSTRACT}

Jansky, S. H., Simon, R., and Spooner, D. M. 2008. A test of taxonomic predictivity: Resistance to early blight in wild relatives of cultivated potato. Phytopathology 98:680-687.

Host plant resistance offers an attractive method of control for early blight (caused by the foliar fungus Alternaria solani), a widespread disease that appears annually in potato crops worldwide. We tested the assumed ability of taxonomy to predict the presence of early blight resistance genes in wild Solanum species for which resistance was observed in related species. We also tested associations to ploidy, crossing group, breeding system, and geography. As in a prior study of Sclerotinia sclerotiorum (white mold) resistance, tremendous variation for resistance to early blight was found to occur within and among species. There was no discernable relationship between the distribution of resistant phenotypes and taxonomic series (based on an intuitive interpretation of morphological data), clade (based on a cladistic analysis of plastid DNA data), ploidy, breeding system, geographic distance, or climate parameters. Species and individual accessions with high proportions of early blight resistant plants were identified, but high levels of inter- and intraaccession variability were observed. Consequently, the designation of species or accessions as resistant or susceptible must take this variation into account. This study calls into question the assumption that taxonomic or geographic data can be used to predict sources of early blight resistance in wild Solanum species.

Additional keywords: disease resistance.
Early blight (EB, caused by the foliar fungus Alternaria solani [Ellis and G. Martin]) is a widespread disease that appears annually in potato crops worldwide (37). Although yield loss may be minimized with fungicides, growers are interested in reducing chemical inputs for both environmental and economic reasons. The development of potato cultivars with resistance to EB would provide an attractive solution to this disease problem. However, all major potato varieties are susceptible to EB. A large study of 934 potato clones from around the world identified few cultivated potato genotypes with early blight resistance (6).

The sexual cycle for $A$. solani has not been identified, but it reproduces asexually via multicellular conidia (17). Primary infection of leaflets occurs from inoculum that has overwintered in soil or plant debris. Typically, senescing leaf tissue is most severely affected by the disease because older leaves are more susceptible and require a shorter incubation period than younger leaves. High relative humidity is required for spore germination and subsequent infection, while dry air aids spore dispersal. A climate with humid nights and dry days provides an optimal environment for the development of early blight. A. solani is distributed worldwide, including all of North and South America (1).

Breeding with resistant wild species germplasm is a major method to combat disease in cultivated potato $(18,26)$. There are approximately 190 wild potato species distributed from the southwestern United States to Chile (42). Species richness is high in central Mexico at $20^{\circ} \mathrm{N}$, and in the southern hemisphere, particularly in the Andean highlands between 8 and $20^{\circ} \mathrm{S}$ (24). Collectively, these species represent a more diverse and accessible

Corresponding author: S. H. Jansky; E-mail address: shelley.jansky@ars.usda.gov

doi:10.1094/PHYTO-98-6-0680

This article is in the public domain and not copyrightable. It may be freely reprinted with customary crediting of the source. The American Phytopathological Society, 2008. germplasm resource than in any other crop $(18,20,34,36)$. Wild potato species are found in an amazingly diverse array of environments, including the high grasslands of the Andes, humid temperate mountain rain forests, mossy branches of trees, and cultivated fields. These wild species contain genes encoding numerous traits not found in cultivars and represent an especially rich source of disease resistance genes $(18,26,40)$. However, we are not aware of any published studies evaluating early blight resistance in a broad array of wild Solanum species.

The genetic diversity in the United States Potato Genebank provides a tremendous resource for potato breeders. However, it is impractical to screen all accessions for disease resistance. Scientists would benefit from a systematic system to search for resistant genotypes. Taxonomic or geographic information may provide such a search strategy. A major justification for taxonomic research is its assumed ability to predict the presence of traits in a group for which the trait has been observed in a representative subset of the group. Taxonomy is regularly used by breeders interested in choosing potential sources of disease resistant germplasm for cultivar improvement. This is our second study designed to test the predictive component of diverse potato (Solanum L. sect. Petota Dumort.) species taxonomies and ecogeography, using disease resistance data. This study focuses on resistance to $\mathrm{EB}$, using 156 accessions of 41 wild relatives of potato and outgroups in Solanum section Etuberosum (Buk. and Kameraz) A. Child. Our first study (27) found tremendous variation for resistance to the fungal disease white mold, (caused by Sclerotinia sclerotiorum (Lib.) de Bary) both within and among species. No consistent associations were observed between white mold resistance and taxonomic series (based on an intuitive interpretation of morphological and crossing data), clades (based on a cladistic analysis of plastid DNA data; Fig. 1), ploidy, breeding system, geographic distance, or climate parameters. Species and individual accessions with high proportions of white moldresistant plants were identified in that study, but both often 
exhibited extensive variation. Jansky et al. (27) concluded that taxonomic relationships and ecogeographic data cannot be reliably used to predict where additional sources of white mold resistance genes will be found.

Jansky et al. (27) summarized the history and theory of claims of taxonomic predictivity, and general theoretical constraints of using disease resistance as a trait to be associated with taxonomy. For example, complex inheritance can reduce predictivity with taxonomy or geography, as the phenotype (disease resistance) may be caused by diverse and nonhomologous genes. However, they also pointed out that (i) complex inheritance patterns were typical with other traits commonly associated with taxonomy, and (ii) taxonomy is often cited as a useful tool for breeders to choose disease resistant accessions. They concluded that additional tests were needed before general conclusions could be made about predictive associations of potato taxonomy and disease. The purpose of our study is to provide such an additional test.

In addition to associations of disease resistance to species, we designed our study to test associations to series (groups of putatively interrelated species as determined by intuitive methods as inferred by Hawkes [20]), to plastid-based molecular clades (Fig. 1), ploidy, crossability groups, breeding system, geographic distance, and climatic parameters. Ploidy levels of wild Solanum species range from diploid $(2 n=2 x=24)$ to hexaploid $(2 n=6 x=$ 72) with about $70 \%$ of the species diploid (22). Many wild species are intercrossable with each other and to the cultivated potato. Ploidy does not always predict crossing success in potato, and species are often classified according to "effective" ploidy rather than actual ploidy. Johnston and Hanneman (29) and Johnston et al. (28) proposed that the success of interspecific crosses depends on a proper balance of genetic factors contributed by gametes to the endosperm. Solanum species have consequently been assigned endosperm balance numbers (EBN) based on their ability to hybridize with each other (19). Barring other crossing barriers, successful hybridization is expected when male and female gametes have matching EBN values. Ploidy (EBN) combinations include $2 \times(1 \mathrm{EBN}), 2 \times(2 \mathrm{EBN})$ (including most wild species), $4 \times(2 \mathrm{EBN}), 4 \times(4 \mathrm{EBN})$ (including tetraploid potato cultivars), and $6 \times(4 \mathrm{EBN})$.

The objective of our study was to determine whether early blight resistant phenotypes in wild potato germplasm are associated with taxonomic species, series, clade, ploidy, EBN, breeding system, geographic distance, or climatic parameters.

\section{MATERIALS AND METHODS}

Plant material. The approximately 5,000 cultivated and wild potato accessions in the United States Potato Genebank (NRSP-6) in Sturgeon Bay, Wisconsin, were originally collected in 12 countries in the Americas, covering most of the distribution area of wild potatoes that occur from Colorado (United States) to Chile and Uruguay. Our study included 14 of the 19 tuber-bearing series of Hawkes (20) and all four clades of sect. Petota based on plastid restriction site phylogenies as discovered by the combined studies of Spooner et al. (39), Rodríguez and Spooner (35), Castillo and Spooner (10), and Spooner and Castillo (41) (Fig. 1). We obtained true potato seed from NRSP-6, and planted between one and six accessions of each of 39 ingroups (sect. Petota) and two outgroups (sect. Etuberosum, including S. etuberosum Lindl. and $S$. palustre Poepp.). These accessions represent the majority of the range of the species (Fig. 2). Most species (29) were

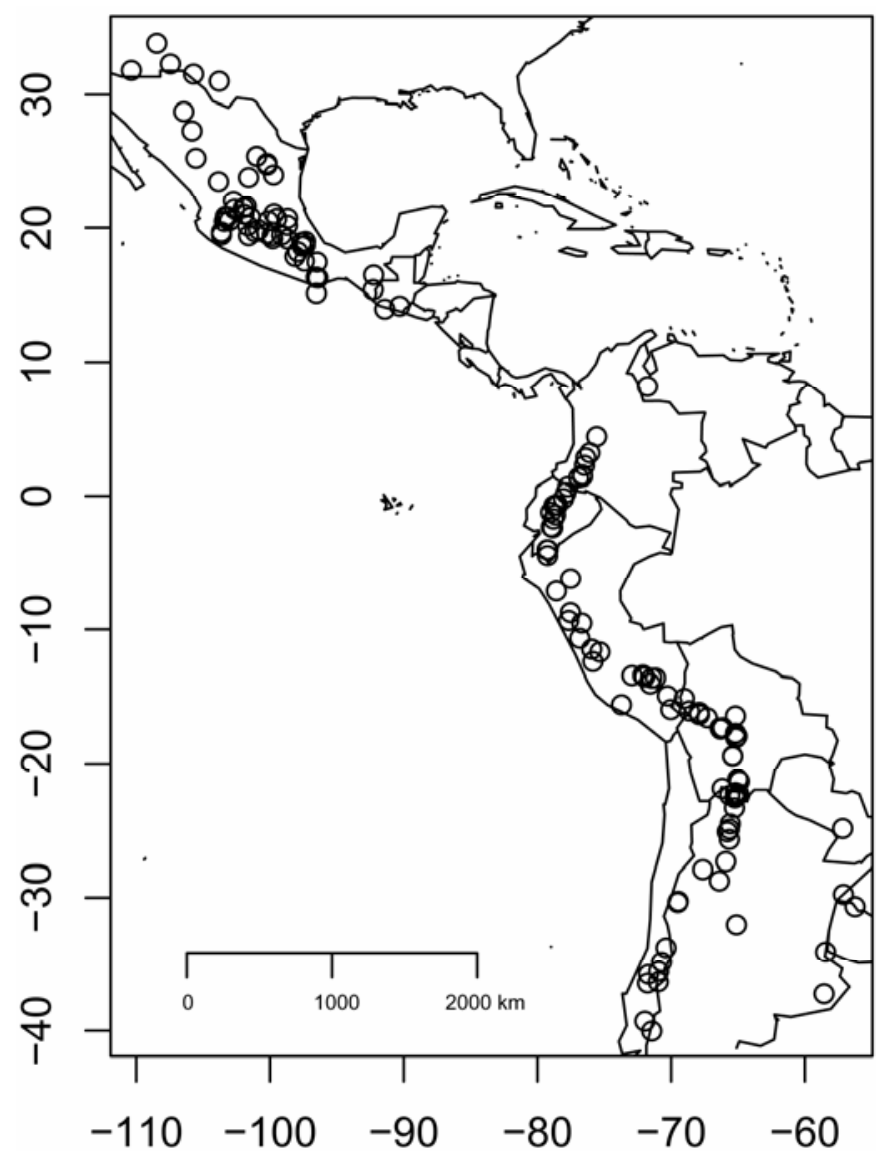

Fig. 2. Geographic localities of accessions.

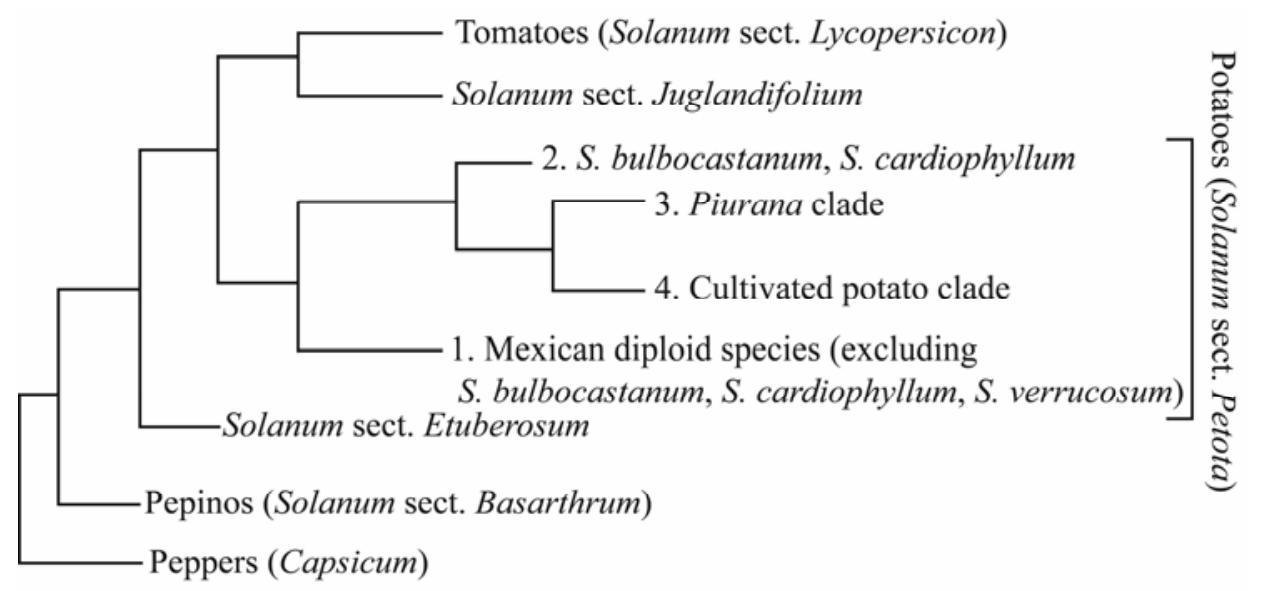

Fig. 1. Cladistic relationships of potato, tomato, and outgroups, sensu Spooner and collaborators as described in text, showing the four clades in potato (1 to 4) and outgroups. 
represented by four accessions. Species names follow recent taxonomic changes as outlined in Spooner and Salas (42).

Disease screening. Typically, potato clones are evaluated for EB resistance by observing lesion development following a natural infestation in the field. As plants senesce, the pathogen infects leaves, allowing plants to be scored for lesion incidence and size. Wild potato species cannot be evaluated in this way because they do not senesce under the long days of temperate zone summers. However, an in vitro assay provides an alternative method to evaluate EB resistance in wild potato species (7). This assay uses auxin to promote senescence in detached leaves, which are inoculated with a conidial suspension of $A$. solani. This test reproduced the field resistance reaction of a set of cultivars displaying a wide range of maturity types and levels of early blight resistance.

Seeds were soaked in 1,500 ppm gibberellic acid for $24 \mathrm{~h}$ to break dormancy. Approximately 100 seeds of each of 156 accessions were then sown in flats in a peat-based potting mix (ProMix) on 21 April 2006, and grown in a greenhouse with an $18 \mathrm{~h}$ photoperiod. Due to poor seed germination or low seedling vigor, 12 accessions were eliminated from the trial. On 12 May, 12 seedlings of each accession were transplanted to individual peat pots. On 12 June, the oldest healthy leaf was collected from each plant and the petiole was inserted into $0.5 \%$ agar containing $10.7 \mathrm{mM}$ auxin (1-naphthalene acetic acid) and tetracycline at $10 \mu \mathrm{g} / \mathrm{ml}$ in a petri dish. Three leaves (from three different plants) were placed on a plate. The next day, a mister was used to apply a 47,000 $\mathrm{CFU} / \mathrm{ml}$ conidial suspension of $A$. solani (potato isolate) to the upper surface of each leaf. Petri dishes were incubated under continuous fluorescent light at $27^{\circ} \mathrm{C}$. After $72 \mathrm{~h}$, individual leaves were scored based on severity of lesion development, from 0 (no lesions) to 4 (severe symptoms). One week later, a second replication was performed using the same plants and an inoculum density of 48,000 CFU/ml. Again, the oldest healthy leaf was sampled. A third replication was carried out 1 week after that, using 43,000 CFU/ml inoculum.

Statistical analyses of taxonomic traits. The mixed models analysis in SAS was used to analyze variation due to species, series, clade, breeding system, ploidy, and endosperm balance number. Means separation was carried out using the Tukey test.

Spatial analyses. We analyzed spatial and environmental variables to test whether geographic provenance of accessions is a predictor of disease resistance. The analyzed response variable was the EB resistance mean score per accession. The main goal of this analysis was to determine which variables are good predictors of resistance levels. We used two strategies for analysis: (i) fitting a linear model accounting for spatial autocorrelation, if any; and (ii) using a rule discovery technique called regression trees, based on the results from strategy 1. Lastly, any significant spatial or environmental decision rules were applied to map disease resistance scores and to analyze how species relate to predicted geographic areas of low and high scores.

Data preparation. A database with spatial and environmental data was constructed by calculating means of EB scores per accession, annotated with latitude and longitude data. A spatial query was conducted to associate altitude, monthly mean minimum and maximum temperature, and monthly precipitation data from a georeferenced global climate database using DIVA-GIS software (23). Further, latitude was included in initial analysis for its relation to day length. Thus, 38 variables for the environment were used. For geostatistical calculations, we used the statistical software R (25) and the add-on packages spatstat (2), spdep (5), fields (32), spatial (45), lattice (38), and rpart (43). The data were loaded as georeferenced points to apply spatial visualization, following the process described in the "spatstat" library. The coordinates were extracted to construct a limiting surrounding polygon using the function "ripras," since the dataset was obtained without a specified observation window. Accession occurrences were visualized on a map.
Testing for significant spatial autocorrelation. In geography, the value of a variable at a certain location may often depend on the values of nearby variables. For example, the temperature at point $\mathrm{X}$ is more similar to the temperature at a point, say, a distance of $1 \mathrm{~km}$ away than to the temperature at a point $1,000 \mathrm{~km}$ away. Such dependencies or correlations violate assumptions regarding normal distribution. Spatial autocorrelation refers to the dependency of one variable value on other neighboring variable values. Patterns of autocorrelation in spatial data may create false positive results. The most commonly used autocorrelation index is Morans I statistic, which calculates correlation coefficients between spatial neighbors. That is, variables at a given calculation can be predicted from its spatial neighbors. Morans I may vary between -1 (unlike) and +1 (like). Values around 0 indicate randomness (12); values above absolute 0.1 are considered high (14). Significance was assessed with a Bonferroni test.

Fitting a linear model. We used an eigenvalue filtering approach to build a model taking into account spatial autocorrelation similar to the protocol used in Jansky et al. (27). The spatial filter method consists basically of extracting positive eigenvectors from a connectivity matrix and using them directly as spatial predictors or filters in a regression framework. Eigenvectors with high positive eigenvalues tend to capture large-scale spatial effects; those with smaller values detect more local patterns. The method allows adding eigenvectors until the residuals minimize spatial autocorrelation as tested by the Morans coefficient. For the initial model, we included taxonomic data and spatial and environmental variables to assess relative significance. We used analysis of variance (ANOVA) to test models for significance. Two general models were compared, one including all variables plus fitted eigenvalues of spatial autocorrelation and one without fitted eigenvalues.

Regression trees using recursive partitioning. A priori, it is not clear what kind of relationship to expect between potential geographical or environmental predictors and disease scores. That is, the relationship may be linear, nonlinear, or a combination of both. Regression trees were developed to address such possible nonlinear relationships between response and independent variables. We analyzed the data using the package "rpart." The optimal tree was determined using the minimal estimate of cross validated prediction error for different numbers of splits (16). For the initial model, we used only those spatial and environmental variables that were found significant in the ANOVA of the linear model. The prediction rules from the regression tree were employed to construct maps of low and high score values.

Relation of species with environmental predictions. The results from the decision tree were further used to group accessions into two extreme classes of low and high average scores. The results of the grouping were analyzed with respect to the distribution of disease score values of each accession in the extreme groups and with regard to unique and overlapping species between the two extreme groupings.

\section{RESULTS}

Taxonomy. Comparisons among species. Significant $(P<0.05)$ differences in mean early blight scores were detected among the 41 species in the trial (Fig. 3). The most resistant species was $S$. neorossi Hawkes and Hjert., an Argentinean diploid species with an undetermined EBN, with a mean score of 0.66. However, this species was represented by only one accession. The next most resistant species, represented by six accessions, was $S$. commersonii Dunal, a diploid 1 EBN species found in the Southern Cone of South America (Argentina, Brazil, and Uruguay). It had a mean score of 0.73 . The most susceptible was $S$. colombianum Bitter, with a mean score of 2.2. This is a tetraploid $2 \mathrm{EBN}$ species found in the northern regions of South America (Colombia, Equator, and Venezuela). 
Comparisons among and within accessions of the same species. Significant differences $(P<0.05)$ among accessions within a species were detected for 25 of the 39 species $(64 \%)$ in which two or more accessions were evaluated. For example, $S$. commersonii is the most resistant species for which multiple accessions were evaluated. The median score for five accessions was 2 , but most scores in one accession were 2 or 3 , while most scores in another were 1 or 2 . The sixth accession, on the other hand, had scores of 0 or 1 , with a median score of 0 .

Comparisons among series, plastid DNA-based clade, breeding system, ploidy, and EBN. Species were grouped by series, plastid DNA-based clade, and ploidy, to explore their predictive component. Significant differences were detected among series (Fig. 4). The two most resistant series were Commersoniana Buk. and Bulbocastana (Rydb.) Hawkes. However, each of these series is represented by only a single species, $S$. commersonii and $S$. bulbocastanum Dunal, respectively. These are among the most resistant species (Fig. 3). The most resistant species, however, is $S$. neorossii in series Tuberosa (Rydb.) Hawkes. Members of this series range from very resistant to susceptible. The two most susceptible species, S. violaceimarmoratum Bitter and S. colombianum, are in series Conicibaccata Bitter. However, $S$. paucijugum Bitter is also in this series and is relatively resistant.

The five clades were significantly different from each other $(P<0.05)$. The most resistant was clade 2 , with a mean score of 1.32 , while the most susceptible was the outgroup, Solanum section Etuberosum, with a mean score of 2.04 (Fig. 5). Clade 2 contains one of the most resistant species, $S$. bulbocastanum, but it also contains the moderately resistant species $S$. cardiophyllum Lindl. (Fig. 3). Although clade 2 has the lowest mean resistance score, the most resistant species are in clade 4. This clade also contains a number of susceptible species, resulting in a low mean score for the clade. The outgroup is the most susceptible clade because it contains the two susceptible species $S$. etuberosum and S. palustre.

This trial included 22 outcrossing species, 17 inbreeding species, and two species for which the breeding system has not been determined. A significant difference $(P<0.0001)$ was detected for breeding system, with outbreeders expressing more early blight resistance (mean score 1.61) than inbreeders (mean score 2.01). The seven most resistant species (with the exception of $S$. neorossi, for which the breeding system is not known) are all outcrossers. Both inbreeding species and outbreeding species were among the most susceptible species.

Significant differences $(P<0.05)$ in EB resistance were also detected among ploidy levels. All three ploidy levels were significantly different from each other. The diploid species were the most resistant (mean score 1.63), while the tetraploid species were the most susceptible (mean score 1.96). The hexaploid species were intermediate (mean score 1.79). The diploid group included the eight most resistant species, while the tetraploid group included four of the twelve most susceptible species (Fig. 3 ). All groups, however, contained both resistant and susceptible species.

The 1 EBN species (mean score 1.26) were much more resistant than the 2 EBN and 4 EBN species, which were not different from each other (mean score for both 1.78). The most resistant species is $S$. neorossii, for which EBN has not yet been determined (Fig. 3). Three of the ten most resistant species are 1 EBN. However, some of the most susceptible species ( $S$. jamesii Torr. and $S$. immite Dunal) are also $1 \mathrm{EBN}$.

Biogeography. Autocorrelation. The test for spatial autocorrelation (results not shown) documents highly significant correlations at very short and very large distances. This corresponds to small pockets of similar values.

Spatial and environmental predictors as assessed by fitting a linear model. Linear models with and without the fitted auto- correlation component were compared with an ANOVA showing that the model including the spatial eigenvalues was significantly better $(P<0.05)$ for only nine variables: altitude, latitude, species, EBN, minimum temperature in April, minimum temperature in October, maximum temperature in November, rainfall in July, and the fitted autocorrelation. The variables species and EBN were included in the spatial analysis to assess the relative usability of spatial and environmental variables as predictors. The most significant variable $(P=0.1)$ was species.

Prediction of early blight score by environmental factors. The most significant spatial and environmental variables without the fitted autocorrelation were further used in a linear model of a regression tree as a complementary analytical tool. By selecting an optimal tree, a simple rule was discovered that separates early

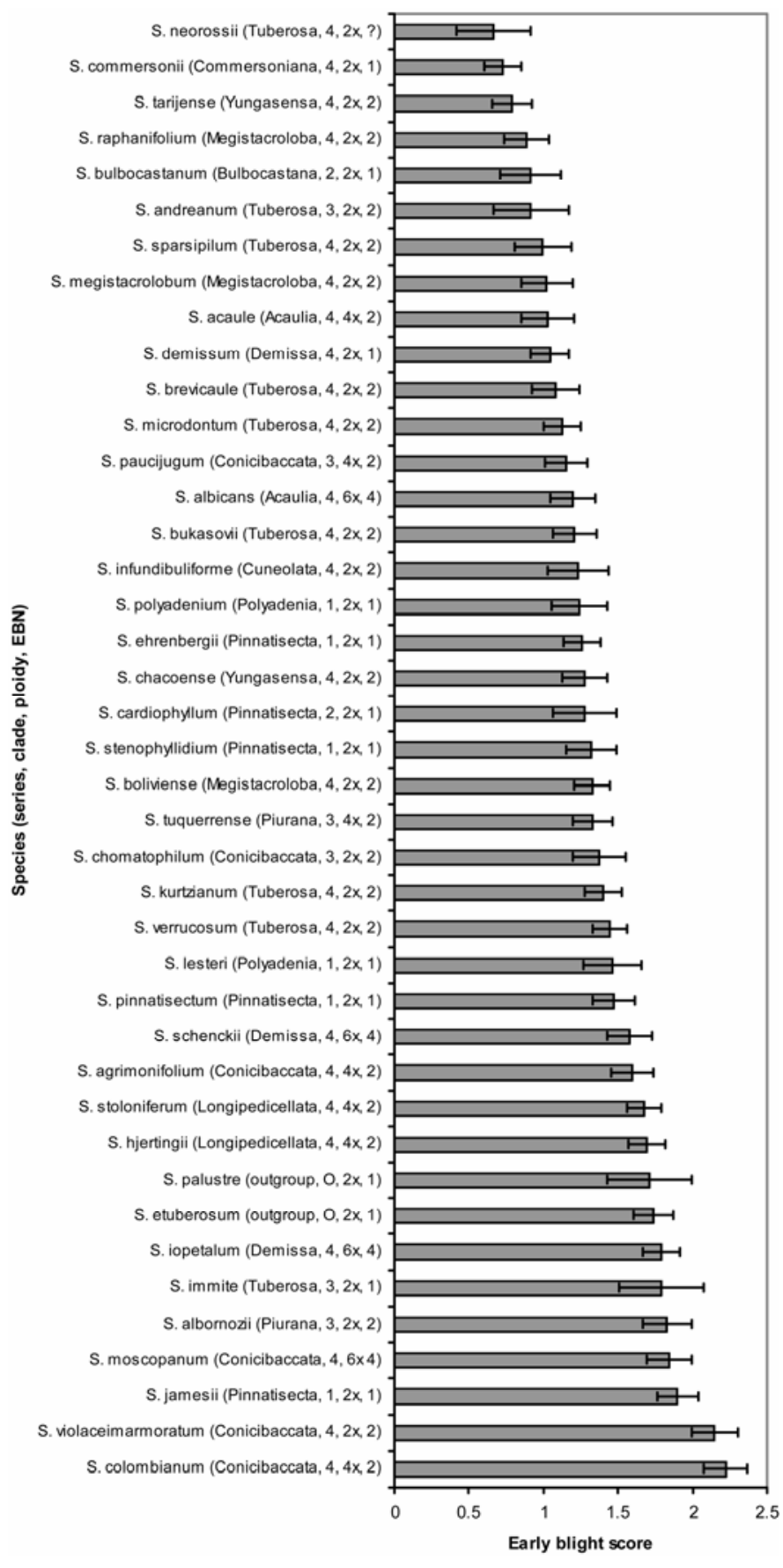

Fig. 3. Mean early blight resistance scores $(0=$ resistant, $4=$ susceptible) for 41 wild Solanum species. Each error bar is plus and minus one standard deviation. Data in parentheses include series, clade, ploidy, and endosperm balance numbers (EBN). EBN has not been determined for S. neorossii. 
blight scores into two significant distinct classes. The rule states that lower early blight scores (1.4) can be predicted from the monthly average rainfall in July below $23.25 \mathrm{~mm}$; higher values (1.7) correspond to rainfall higher than $23.25 \mathrm{~mm}$ in July.

Association of species response by environmental class. We used the same rule to separate accessions into two subsets to determine whether species associate with this rainfall pattern and, if so, which species are associated. The two sets separate almost completely according to species, with only a few species appearing in both sets. Accessions from three species ( $S$. chacoense Bitter, S. chomatophilum Bitter, and S. paucijugum) appear in both groups. Eighteen species constitute the group with lower

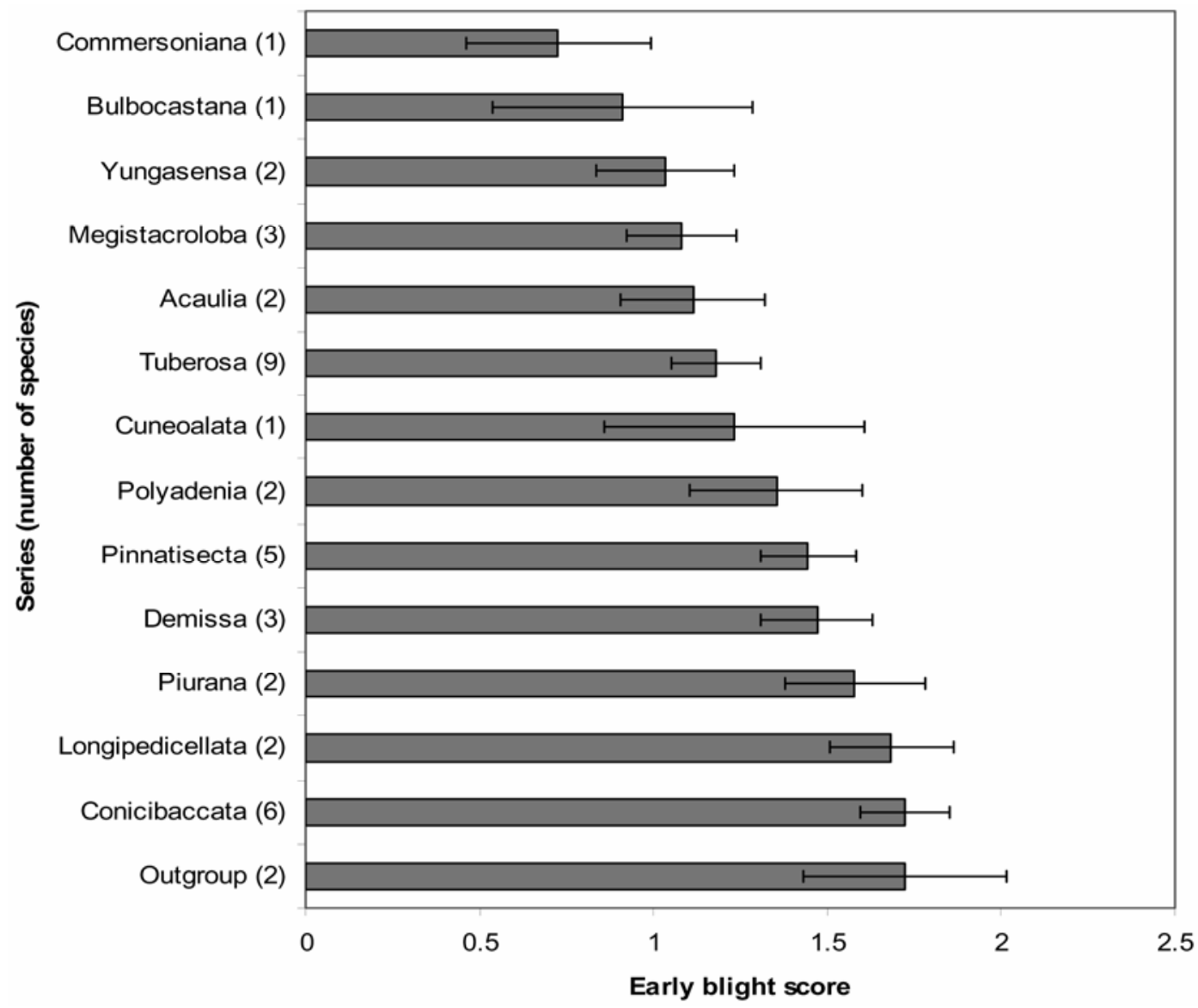

Fig. 4. Mean early blight resistance scores $(0=$ resistant, $4=$ susceptible $)$ for 14 series. Each error bar is plus and minus one standard deviation. The number of species in each species is indicated in parentheses.

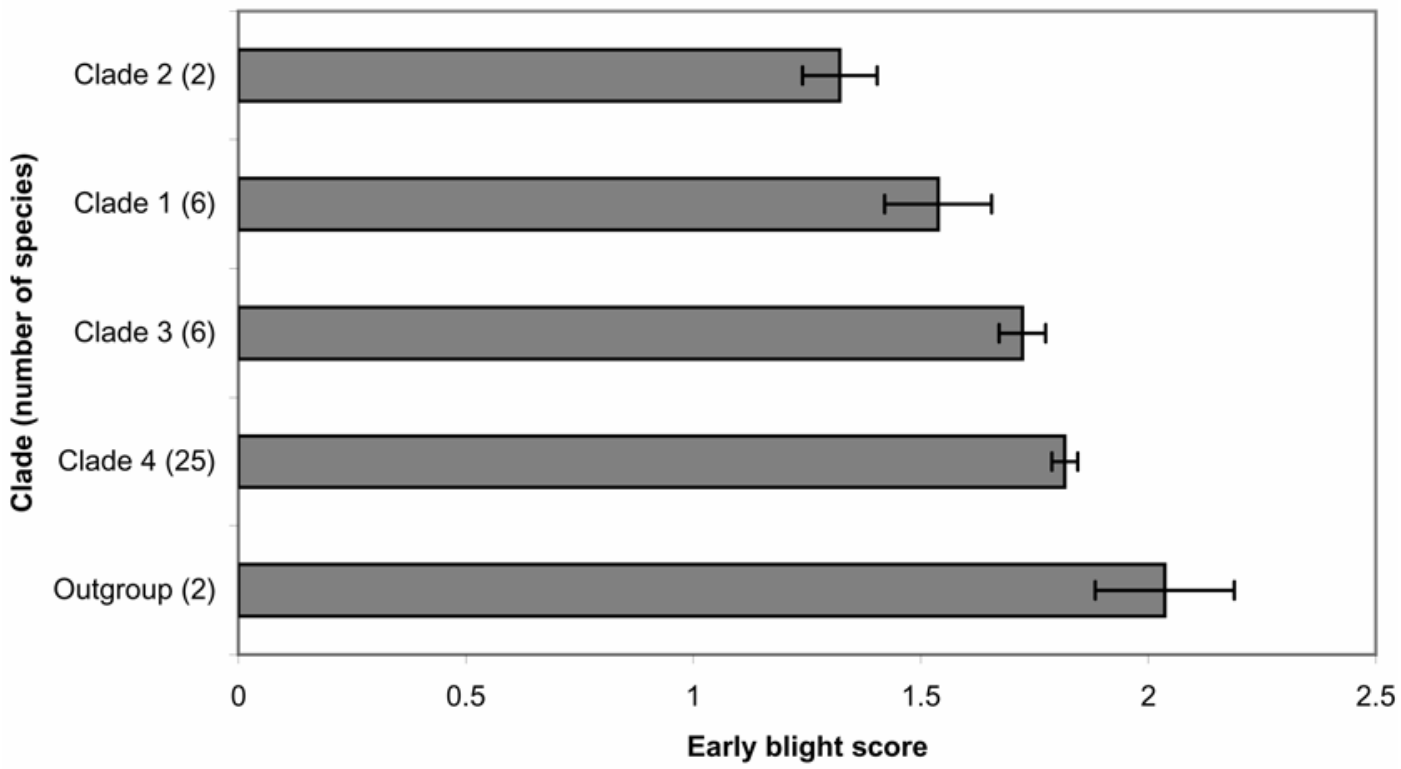

Fig. 5. Mean early blight resistance scores $(0=$ resistant, $4=$ susceptible $)$ for four chloroplast-based molecular clades and the outgroup. Each error bar is plus and minus one standard deviation. The number of species in each species is indicated in parentheses. 
scores (resistant) and 26 the group with higher scores. While the resistant group shows uniform score patterns across species, with only one notable exception (S. violaceimarmoratum), the susceptible group consists of species with widely different ranges of score patterns. The two subsets further showed distinct patterns of association with altitude, with the more resistant group found in altitudes above $3,000 \mathrm{~m}$ while the more susceptible accessions associate with altitudes below 2,500 m (figures not shown).

\section{DISCUSSION}

Potato breeders have access to tremendous genetic variation in wild Solanum relatives. The United States Potato Genebank maintains a collection of 5,000 accessions from which breeders can choose for resistance evaluations. This number is too large for practical screening studies, so it would be valuable to have a strategy to systematically search for resistant genotypes. It seems logical to use taxonomic or geographic information to refine the search strategy. Although we found significant differences for early blight resistance among species, taxonomic series, plastidbased molecular clades, ploidy levels, endosperm balance numbers, and breeding systems, resistant species were not clustered consistently in any of these groups. Therefore, a breeder could not use these groupings as reliable predictors for early blight resistance.

The most resistant species were $S$. neorossii, S. commersonii, and $S$. tarijense Hawkes. An analysis of multiple accessions of the latter two species shows that breeders would likely find resistant accessions in these species, but they could also easily find susceptible accessions, so these resistances are not species-specific. Variation among accessions is common, and variability even exists within accessions, with outliers common. This is not surprising, since many of the species in this trial are highly heterozygous outcrossers. Even the inbreeding species are expected to be heterozygous because they are maintained by intercrossing at the genebank. Because of this variability, fine screening to identify individual clones with desired traits has been implemented in potato $(3,4,15,47)$.

It is interesting that diploid $1 \mathrm{EBN}$ species are more resistant to early blight than $2 \mathrm{EBN}$ or $4 \mathrm{EBN}$ species. These species are commonly reported to be rich sources of resistances to diseases, pests, and environmental stresses $(8,9,20,21,30,31,44,47)$. Unfortunately, these species are also more difficult to introgress into the cultivated potato than are diploid 2 EBN species. There are a few diploid 2 EBN species with high levels of early blight resistance, including $S$. tarijense and $S$. raphanifolium Cárdenas and Hawkes. Efforts are currently underway to introgress resistant clones from these species into germplasm of the cultivated potato, $S$. tuberosum $\mathrm{L}$. Adapted clones will be evaluated in the field to determine whether high levels of resistance can be combined with early maturity. Inheritance studies are also being carried out to determine the genetic basis of early blight resistance in wild Solanum species.

A. solani is distributed worldwide (1). However, local environmental conditions may or may not favor disease development, resulting in variable selection pressure for early blight resistance. Disease is most likely to develop under optimal day time temperatures for mycelial growth $\left(28^{\circ} \mathrm{C}\right)$, optimal night time temperatures for sporulation $\left(20^{\circ} \mathrm{C}\right)$, dry conditions (typically during the day) for spore dispersal, and free water or high humidity (often at night) for spore production and germination (17). These microclimatic influences cannot be detected from GIS data, which are available only on a broad scale. For example, in the northern hemisphere a south facing mountain slope may be too dry for spore germination, but the north side at the same altitude may provide the humidity required for disease development. Similarly, rainfall amounts may be similar for two locations, but the rain may occur more frequently and in smaller doses at one location, influencing disease development. In an attempt to elucidate differences due to microenvironment, we studied habitat notes provided by the taxonomists who collected the accessions used in our study. The four most resistant accessions for which we have habitat data were all collected in or adjacent to cornfields. Furthermore, when accessions were grouped, 9 of the 28 accessions $(32 \%)$ in the most resistant third were collected from cultivated fields, while all of the 28 accessions in the most susceptible third were from wild sites. We presume that potatoes are a rotation crop in these fields and that wild Solanum species and other solanaceous plants act as intermediate hosts in years when potatoes are not grown. Disease pressure would be stronger in the monoculture environment at these sites than in the more remote wild areas where other accessions were collected. Consequently, for diseases caused by airborne spores, wild species accessions collected near agricultural fields may be more resistant than those collected in forests or other wild areas. Variation among accessions of the same species would be expected, since some are more closely associated with agricultural fields than others. A limitation of habitat data, though, is that descriptions of microenvironmental conditions on germplasm accessions are variable in detail and limited in scope. For example, one description indicated that a population was collected under a stand of oak trees. However, it is impossible to know from this information whether agricultural fields are distant or nearby. In addition, the description does not indicate whether the site has the appropriate conditions for disease development.

Another microenvironmental variable, pathogen population variability, may confound our results. Isolates of $A$. solani differ in virulence, indicating that physiological races may exist (46). We are working under the assumption that resistance to the $A$. solani isolate derived from cultivated potatoes in Wisconsin confers resistance to isolates found in areas where wild Solanum species occur and that, furthermore, there is no functional variation among those isolates. However, we are not in a position to test that assumption.

While the spatial analysis did not reveal any strong trends, the environmental analysis determined a rule relating to a single factor, the rainfall pattern in the month of July. Interestingly, this rule defines regions almost entirely on the Southern Cone where the growing period for wild potato species is between October and May, while July is the coldest month. Thus, the rule does not relate directly to any temperature or precipitation variables of wild potatoes nor the fungus during the growing and interaction period. Therefore, it seems of little practical value as it has to be considered that the spatial analysis is based on inferences via provenance annotation of accessions and not on actual responses measured on site.

Daly et al. (13) suggest that traits such as the synthesis of a nonprotein amino acid, glucosinolate production, nitrogen fixation, and taxol biosynthesis illustrate the predictive nature of taxonomy. However, these post hoc associations of taxonomy to traits were carried out at a much higher level classification (between families and orders) than our studies carried out among closely related species of a subset of a genus (Solanum sect. Petota). It appears from this study and the previous white mold study (27), that at least some disease resistance traits in potato can not be predicted at the species, clade, or series level.

Genetic studies using diploid cultivated potato populations have identified high heritability values for early blight resistance $(11,33)$. These data indicate that resistance is not controlled by a single major gene, but it is probably controlled by at least a few genes. In wild species populations, genetic drift may occur for the set of genes associated with resistance, especially if selection pressure is weak.

We conclude that, while there are some broad trends of associations of early blight resistance to taxonomic species, series, clade, ploidy, breeding system, geographic distance, and climatic 
parameters, there is so much variation within these groupings that they have little practical utility to identify sources of early blight resistance. This is similar to our previous finding for white mold resistance (27). There are many similarities between white mold and early blight which may explain why the results from both studies are similar. Both diseases are caused by foliar pathogens, which can travel large distances via airborne spores, although the spores of $A$. solani are asexual, while those of $S$. sclerotiorum are sexual. The distributions of both pathogens are widespread, with a broad host range. In addition, both pathogens require free water for spore germination, and disease develops rapidly at moderate temperatures (around $25^{\circ} \mathrm{C}$ ). Consequently, disease development is expected to occur in similar climates. Finally, while both diseases reduce the photosynthetic capacity of host plants, they typically do not cause plant death. Selection pressure may not be as severe as that for a disease which causes rapid plant death, such as late blight.

This study addresses the fundamental and widely-accepted biological assumption that taxonomic and biogeographical variables are predictive. Efforts to utilize wild crop germplasm rely on the belief that taxonomic relationships can guide the selection of useful sources of resistance genes. Results from both the white mold and early blight studies call into question this paradigm of prediction. Although reliable predictors of resistance traits have not been identified, this research highlights the need to consider other options for the identification of sources of disease resistance genes.

We are continuing studies with resistances to other pests and diseases of wild potatoes to determine whether other traits in wild potato species may follow the prediction paradigm. For example, we plan to evaluate resistance to a viral disease (Potato virus Y), which is under simple genetic control. We are also scoring the same accessions for resistance to the Colorado potato beetle, a trait with multiple resistance mechanisms. Potato virus $Y$ causes severe stunting and is perpetuated through tuber generations, while the Colorado potato beetle causes severe defoliation and plant death in a short period of time. Perhaps selection pressure for these traits is stronger than that for early blight and white mold, providing more predictive power.

\section{ACKNOWLEDGMENTS}

We thank the International Potato Center, the United States Department of Agriculture, and NSF DEB 0316614 to D. Spooner entitled "A world-wide treatment of Solanum" for funds. Germplasm was provided by the United States Potato Genebank (NRSP-6). Names are necessary to report data. However, the USDA neither guarantees nor warrants the standard of the product, and the use of the name by USDA implies no approval of the product to the exclusion of others that may also be suitable.

\section{LITERATURE CITED}

1. Anonymous. 1983. Distribution Maps of Plant Diseases, Number 89. Commonwealth Mycological Institute, Kew, England.

2. Baddeley, A., and Turner, R. 2005. Spatstat: An $R$ package for analyzing spatial point patterns. J. Stat. Softw. 12:1-42.

3. Bamberg, J. B., Longtine, C., and Radcliffe, E. B. 1996. Fine screening Solanum (potato) germplasm accessions for resistance to Colorado potato beetle. Am. J. Potato Res. 73:211-223.

4. Bamberg, J. B., Martin, M., and Kreuger, A. R. 1998. Fine screening potato (Solanum) species germplasm for tuber calcium. Am. J. Potato Res. 75:181-186.

5. Bivand, R., Anselin, L., Berke, O., Bernat, A., Carvalho, M., Chun, Y., Dormann, C., Dray, S., Halbersma, R., Lewin-Koh, N., Ono, H., PeresNeto, P., Tiefelsdorf, M., and Yu, D. 2005. spdep: Spatial dependence: Weighting schemes, statistics and models. R package version 0.3-32.

6. Boiteux, L. S., Reifschneider, F. J. B., Fonseca, M. E. N., and Buso, J. A. 1995. Search for sources of early blight (Alternaria solani) field resistance not associated with vegetative late maturity in tetraploid potato germplasm. Euphytica 83:63-70.
7. Bussey, M. J., and Stevenson, W. R. 1991. A leaf disk assay for detecting resistance to early blight caused by Alternaria solani in juvenile potato plants. Plant Dis. 75:385-390.

8. Cardi, T., Puite, K. J., Ramulu, K. S., D’Ambrosio, F., and Frusciante, L. 1993. Production of somatic hybrids between frost tolerant Solanum commersonii and $S$. tuberosum: protoplast fusion, regeneration and isozyme analysis. Am. Potato J. 70:753-765.

9. Carputo, D., Cardi, T., Palta, J. P., Sirianni, P., Vega, S., and Frusciante, L. 2000. Tolerance to low temperatures and tuber soft rot in hybrids between Solanum commersonii and Solanum tuberosum obtained through manipulation of ploidy and endosperm balance number (EBN). Plant Breed. 119:127-130.

10. Castillo, R., and Spooner, D. M. 1997. Phylogenetic relationships of wild potatoes, Solanum series Conicibaccata (sect. Petota). Syst. Bot. 22:4583.

11. Christ, B. J., and Haynes, K. G. 2001. Inheritance of resistance to early blight disease in a diploid potato population. Plant Breed. 120:169-172.

12. Cliff, A. D., and Ord, J. K. 1981. Spatial processes: Models and Applications. Pion Limited, London, UK.

13. Daly, D. C., Cameron, K. M., and Stevenson, D. M. 2001. Plant systematics in the age of genomics. Plant Physiol. 127:1328-1333.

14. Diniz-Filho, J. A., and Bini, L. M. 2005. Modelling geographical patterns in species richness using eigenvector-based spatial filters. Global Ecol. Biogeogr. 14:177-185.

15. Douches, D. S., Bamberg, J. B., Kirk, W., Jastrzebski, K., Niemira, B. A., Coombs, J., Bisognin, D. A., and Felcher, K. J. 2001. Evaluation of wild Solanum species for resistance to the US-8 genotype of Phytophthora infestans utilizing a fine-screening technique. Am. J. Potato Res. 78:159165.

16. Everitt, B. S., and Hothorn, T. 2006. A Handbook of Statistical Analysis Using R. Chapman and Hall/CRC Press, Boca Raton, FL.

17. Franc, G. D., and Christ, B. J. 2001. Early Blight. Pages 22-23 in: Compendium of Potato Diseases, 2nd ed. W. R. Stevenson, R. Loria, G. D. Franc, and D. P. Wieingartner, eds. The American Phytopathological Society, St. Paul, MN.

18. Hanneman, R. E., Jr. 1989. The potato germplasm resource. Am. Potato J. 66:655-667.

19. Hanneman, R. E., Jr. 1994. Assignment of endosperm balance numbers to the tuber-bearing Solanums and their close non-tuber-bearing relatives. Euphytica 74:19-25.

20. Hawkes, J. G. 1990. The Potato: Evolution, Biodiversity, and Genetic Resources. Smithsonian Institution Press, Washington, D.C.

21. Helgeson, J. P., Pohlman, J. D., Austin, S., Haberlach, G. T., Wielgus, S. M., Ronis, D., Zambolim, L., Tooley, P., McGrath, J. M., James, R. V., and Stevenson, W. R. 1998. Somatic hybrids between Solanum bulbocastanum and potato: A new source of resistance to late blight. Theor. Appl. Genet. 96:738-742.

22. Hijmans, R., Gavrilenko, T., Stephenson, S., Bamberg, J., Salas, A., and Spooner, D. M. 2007. Geographic and environmental range expansion through polyploidy in wild potatoes (Solanum section Petota). Global Ecol. Biogeogr. 16:485-495.

23. Hijmans, R., Guarino, L., Cruz, M., and Rojas, E. 2001. Computer tools for spatial analysis of plant genetic resources: 1 DIVA-GIS. Plant Genet. Res. Newsl. 127:15-19.

24. Hijmans, R. J., and Spooner, D. M. 2001. Geographic distribution of wild potato species. Am. J. Bot. 88:2101-2112.

25. Ihaka, R., and Gentleman, R. 1996. R: A language for data analysis and graphics. J. Comput. Graph. Stat. 5:299-314.

26. Jansky, S. H. 2000. Breeding for disease resistance in potato. Plant Breed. Rev. 19:69-155.

27. Jansky, S. H., Simon, R., and Spooner, D. M. 2006. A test of taxonomic predictivity: Resistance to white mold in wild relatives of cultivated potato. Crop Sci. 46:2561-2570.

28. Johnston, S. A., den Nijs, T. P. M., Peloquin, S. J., and Hanneman, R. E., Jr. 1980. The significance of genic balance to endosperm development in interspecific crosses. Theor. Appl. Genet. 57:5-9.

29. Johnston, S. A., and Hanneman, R. E., Jr. 1980. Support of the endosperm balance number hypothesis using some tuber-bearing Solanum species. Amer. Potato J. 57:7-14

30. Kuhl, J., Hanneman, R., and Havey, M. 2001. Characterization and mapping of Rpil, a late-blight resistance locus from diploid (1EBN) Mexican Solanum pinnatisectum. Mol. Genet. Genomics 265:977-978.

31. McGrath, J. M. W., Christie, E., Haberlach, G. T., Wielgus, S. M., Uchytil, T. F., and Helgeson, J. P. 2002. Introgression and stabilization of Erwinia tuber soft rot resistance into potato after somatic hybridization of Solanum tuberosum and S. brevidens. Am. J. Potato Res. 79:19-24.

32. Nychka, D. 2007. Fields: Tools for spatial data. R package version 3.3.1. http://www.image.ucar.edu/GSP/Software/Fields.

33. Ortiz, R., Martin, C., Iwanaga, M., and Torres, H. 1993. Inheritance of early blight resistance in diploid potatoes. Euphytica 71:15-19. 
34. Peloquin, S. J., Jansky, S. H., and Yerk, G. L. 1989. Potato cytogenetics and germplasm utilization. Am. Potato J. 66:629-638.

35. Rodríguez, A., and Spooner, D. M. 1997. Chloroplast DNA analysis of Solanum bulbocastanum and S. cardiophyllum, and evidence for the distinctiveness of $S$. cardiophyllum subsp. ehrenbergii (sect. Petota). Syst. Bot. 22:31-43.

36. Ross, H. 1986. Potato Breeding-Problems and Perspectives. Verlag Paul Parey, Berlin and Hamberg.

37. Rotem, J. 1994. The Genus Alternaria: Biology, Epidemiology, and Pathogenicity. American Phytopathological Society, St. Paul, MN.

38. Sarkar, D. 2006. Lattice: Lattice Graphics. R package version 0.14-16.

39. Spooner, D. M., Anderson, G. J., and Jansen, R. K. 1993. Chloroplast DNA evidence for the interrelationships of tomatoes, potatoes, and pepinos (Solanaceae). Am. J. Bot. 80:676-688.

40. Spooner, D. M., and Bamberg, J. B. 1994. Potato genetic resources: Sources of resistance and systematics. Am. Potato J. 71:325-337.

41. Spooner, D. M., and Castillo, R. 1997. Reexamination of series relationships of South American wild potatoes (Solanaceae: Solanum sect. Petota): Evidence from chloroplast DNA restriction site variation. Am. J. Bot. 84:671-685.
42. Spooner, D. M., and Salas, A. 2006. Structure, biosystematics, and genetic resources. Pages 1-39 in: Handbook of Potato Production, Improvement, and Post-Harvest Management. J. Gopal, and S. M. Paul Khurana, eds. Haworth Press, Inc., Binghampton, NY.

43. Therneau, T. M., and Atkinson, A. 2006. R port by Ripley B. 2006. rpart: Recursive Partitioning. R package version 3.1-33. S-PLUS 6.x original at http://mayoresearch.mayo.edu/mayo/research/biostat/splusfunctions.cfm

44. Valkonen, J. P. T., Brigneti, G., Salazar, L. F., Pehu, E., and Gibson, R. W. 1992. Interactions of the Solanum spp. of the Etuberosa group and nine potato-infecting viruses and a viroid. Ann. Appl. Biol. 120:301-313.

45. Venables, W. N., and Ripley, B. D. 2002. Modern Applied Statistics with S. 4th ed. Springer-Verlag, New York.

46. Weir, T. L., Huff, D. R., Christ, B. J., and Romaine, C. P. 1998. RAPD-PCR analysis of genetic variation among isolates of Alternaria solani and Alternaria alternata from potato and tomato. Mycologia 90:813-821.

47. Zlesak, D. C., and Thill, C. A. 2004. Foliar resistance to Phytophthora infestans (Mont.) de Bary (US-8) in 13 Mexican and South American Solanum species having EBNs of 1, 2, and 4 and implications for breeding. Am. J. Potato Res. 81:421-429. 